Published in Ecological Economics 2016, 128: 55-67.

\title{
PROCESSES FOR THE SUSTAINABLE STEWARDSHIP OF MARINE ENVIRONMENTS
}

Henrik Scharin ${ }^{1,2}$, Siv Ericsdotter ${ }^{1}$ Michael Elliott ${ }^{3}$, R. Kerry Turner ${ }^{4}$, Susa Niiranen ${ }^{1}$, Thorsten Blenckner ${ }^{1}$, Kari Hyytiäinen ${ }^{5}$, Lassi Ahlvik ${ }^{6}$, Heini Ahtiainen ${ }^{6}$, Janne Artell6, Linus Hasselström ${ }^{7}$, Tore Söderqvist ${ }^{8}$, Johan Rockström ${ }^{1}$

Addresses

1. Stockholm Resilience Centre (SRC), Stockholm University, SE 10691 Stockholm, Sweden

2. Swedish Environmental Protection Agency, SE-106 48 Stockholm, Sweden

3. Institute of Estuarine \& Coastal Studies (IECS), University of Hull, Hull, HU67RX, UK

4. The Centre for Social \& Economic Research on the Global Environment (CSERGE), University of East Anglia, Norwich, NR47TJ, UK

5. Department of Economics and Management, P.O.Box 27, FI-00014 University of Helsinki, Finland

6. Natural Resources Institute Finland (Luke), Helsinki, Finland

7. KTH Royal Institute of Technology, Division of Industrial Ecology, Teknikringen 34, SE-133 31 Stockholm, Sweden

8. Enveco Environmental Economics Consultancy, Måsholmstorget 3, S-127 48 Skärholmen, Sweden

\begin{abstract}
Sustainable stewardship of the marine environment necessitates a holistic approach encompassing all the relevant drivers, activities and pressures causing problems for the natural state of the system and their impact on human societies today and in the future. This article provides a framework as well as a decision support process and tool that could guide such an approach. In this process, identifying costs and benefits of mitigation is a first step in deciding on measures and enabling instruments, which has to be accompanied by analyses regarding distributional effects (ie who gains or loses) related to different targets and policy instruments. As there are risks of future irreversible regime shifts and even system collapses, the assessments have to be broadened to include scenarios on possible future developments as well as ethical considerations. In particular, a deeper sustainable management strategy may be needed to respond to possible future increases in the rate of environmental change, amongst growing evidence of external pressures, interactions and non-linear dynamics. This adaptive management strategy should focus on building the resilience required to cope with and adapt to change
\end{abstract}


Keywords: Adaptive marine management, Baltic Sea, Cost-benefit analysis, Balance sheet approach, future scenarios.

\section{Introduction}

The aim of a sustainable stewardship is to maintain an ecosystem capable of providing a range of ecosystem services now and in the future (Turner, 2000; Elliott, 2014). One challenge lies in understanding the complexity of the processes and functions within the ecosystem and how human behaviour and actions affect the ecosystem and the services and benefits it provides to human societies. Another challenge lies in implementing a strategy that is able to cope with an uncertain future.

The paper focuses on marine ecosystems as examples of complex entities of plant and animal life and their physical environment providing important flows of provisional and cultural ecosystem services (Turner and Schaafsma, 2015). In this context it seeks to provide answers to the following questions: What are the management tools needed to address the environmental problems in marine ecosystems? To what extent can we rely on cost-benefit analysis and environmental impact assessments, and what other considerations might be needed to appropriately guide policies and marine governance?

The paper highlights the different challenges that marine stewardship is facing, and presents an analytical framework to identify the main components of a decision support system (scoping method, process models, indicators, scenarios and socio-economic and political/cultural appraisal) for an adaptive management strategy. The results from two empirical Baltic Sea studies are used to illustrate how this decision support system could be furnished with relevant information. Finally the paper discusses the implications for marine management based on the theoretical framework and the empirical information drawn from different Baltic Sea studies.

\section{The Baltic Sea - environmental challenges and current management}

The governance ${ }^{1}$ of the marine environment is a relationship between two systems: a 'system-to-be-governed' and a 'governing system' (Jentoft, 2007). The system to begoverned consists of the ecosystem and its resources, as well as drivers, activities and pressures affecting the state of the ecosystem, and the impact this has on human wellbeing. The governing system is made up of institutions and steering mechanisms aimed at preserving or improving the state of the ecosystem. Both systems are diverse, complex, dynamic, potentially confusing to users/stakeholders and vulnerable. This complexity requires an integrated governance system which aims to harmonise a number of diverse interests, especially in multi-state regional seas such as European waters in general and the Baltic Sea in Particular (e.g. Boyes and Elliott, 2014, 2015).

\subsection{The system to be governed}

\footnotetext{
1 Governance can be defined as the policies, politics, legislation and administration required or desired by management of an area. This includes the structures and processes for collective decision-making involving both state and non-state (profit and non-profit) actors on different levels - local, regional, national, European and global (Rosenau, 2003).
} 
An understanding of the 'system to be governed' is central to management. That is, understanding the state of the marine ecosystem and its fundamental processes and how it impacts human wellbeing as well as identifying the endogenic and exogenic drivers and pressures affecting the state; exogenic pressures are those operating from outside the system being managed (such as climate change) whereas endogenic pressures are created inside the system (such as fishing) (Elliott, 2011).

The Baltic Sea is globally one of the largest brackish water bodies, containing inflowing seawater from the North Sea and freshwater from its large catchment area (Ducrotoy and Elliott, 2008). It is connected to the Atlantic via the narrow and shallow Danish Straits, which limits water exchange in the Sea and hence the pulses of oxygen-rich water are episodic. Furthermore, its thermohaline and geomorphological characteristics have produced a halocline, which limits the vertical mixing of water and thus the oxygenation of bottom waters (Voipio, 1981; HELCOM, 2007, 2009). These conditions reduce bottom water renewal and the water residence times in the Baltic deeps are up to 40 years causing hypoxia and decreasing the ability of sediments to retain phosphorus (Leppäranta \& Myrberg, 2009; HELCOM, 2007, 2009). The biodiversity of the Baltic Sea has usually been considered as low, but recently Telesh et al. (2011) showed that Baltic Sea species diversity is higher than previously thought.

In particular due to its enclosed nature, the Baltic Sea is vulnerable to internal and external pressures (Elmgren \& Larsson, 2001; Möllmann et al. 2009; Carstensen et al., 2014) and hence its state has changed profoundly during the last centuries, including non-linear and abrupt changes, i.e. regime shifts (Österblom et al., 2007). Such changes become of increasing social concern if they affect ecosystem services and the range of benefits provided to human society. This increases the importance of having holistic assessment tools which convey the overall health for seas such as the HOLAS tool for the Baltic (Borja et al, 2016). Future environmental changes in the structure and processes of the Baltic Sea ecosystem may significantly reduce the functioning of the system (Ducrotoy \& Elliott, 2008) and in turn the production of ecosystem services and their delivery of societal benefits. Model simulations of future Baltic Sea oceanographic conditions, as well as its food web, show previously unobserved ecosystem perturbations (Meier et al., 2012a; Niiranen et al., 2013), and that the risk for future abrupt ecosystem changes cannot be overlooked (Borja et al, 2016).

Anthropogenic nutrient loads have changed the Baltic from an oligotrophic (nutrient poor) to a eutrophic (nutrient rich) state during the last century (de Jonge \& Elliott, 2001; Savchuk et al., 2008). A set of eutrophication-related symptoms denote poor ecosystem health (Tett et al., 2013). The potentially toxic algal summer blooms have increased substantially during the last decades (Kahru \& Elmgren 2014). The proportion of sea floor bottoms with low or no oxygen, and thereby locally reduced benthic fauna and worsened conditions for fish spawning, have also increased substantially (Laine, 2003; Savchuk et al., 2008 and references therein; Carstensen et al. 2014). These pressures together with overfishing, changes in the abundance of seals and climate change have caused several regime shifts in the food web (Figure 1). In the 1950s there was a shift from seal to cod domination (Österblom et al., 2007) followed by a further regime shift in the late 1980s from cod to sprat domination (Möllmann et al., 2009). 


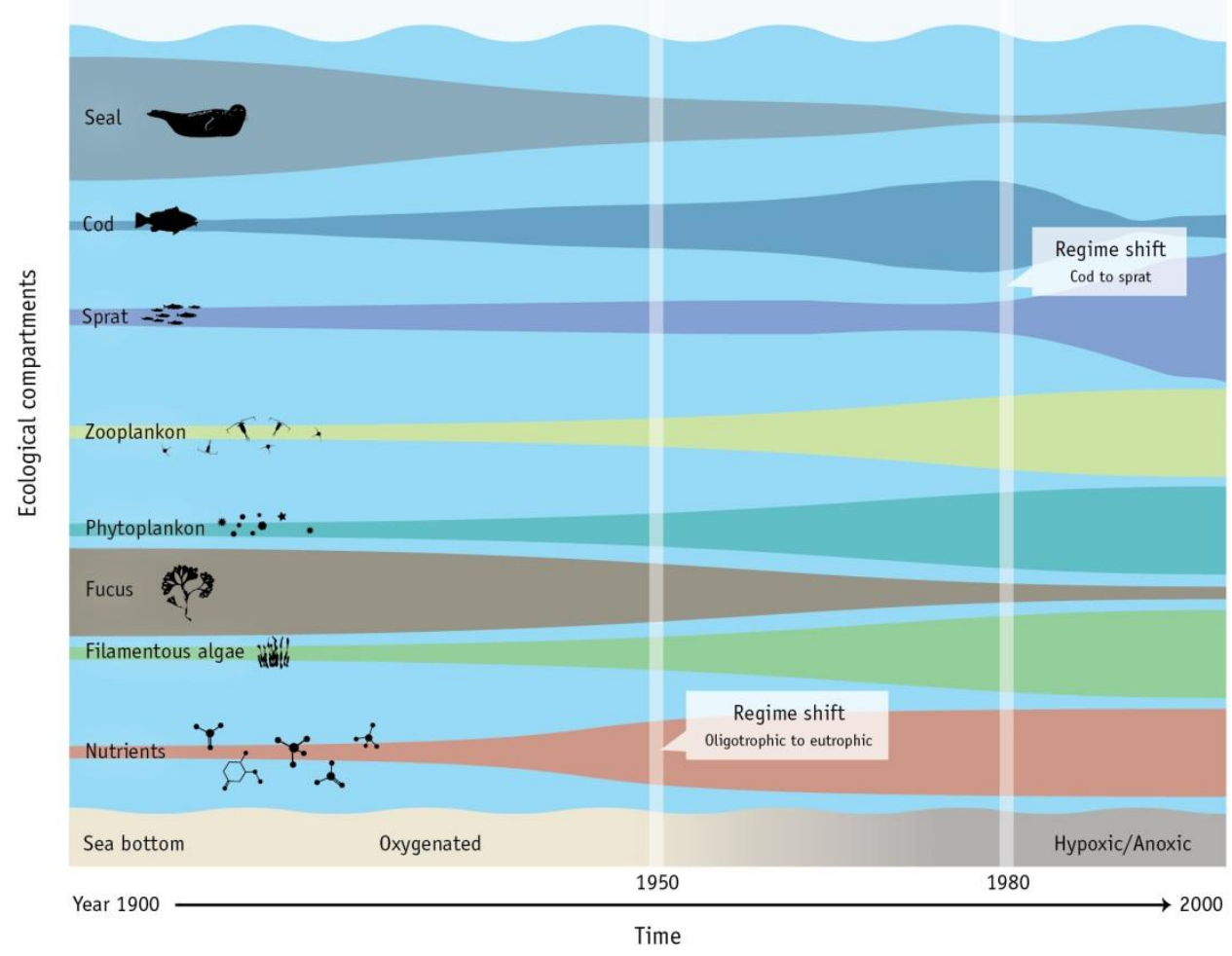

Figure 1. A conceptual model of regime shifts in the Baltic Sea. (SwAM, 2013)

Contamination from hazardous substances, small oil spills and the increased risk of major oil spills, increases in invasive species and marine litter also affect the environmental status of the Baltic Sea. The sea surface temperature has increased by more than $0.7^{\circ} \mathrm{C}$ during the $20^{\text {th }}$ century (Rutgersson et al 2014) and future climate change is projected to have significant impacts on the ecosystem (Meier et al., 2012a and 2012b).

The integrated assessment of the health of the Baltic indicates the cumulative nature of the human impacts (Borja et al, 2016) and hence the management measures required to improve or remediate the system. The changes to the Baltic Sea ecosystem during the last two centuries have been triggered by different drivers, such as population growth, intensification of industry and trade activity as well as related land use changes ( $O^{\prime}$ Neill et al., 2014). Within society this economic growth has been associated with changes in consumption patterns, e.g., increased meat in the diet as well as increases in energy use and traffic (Gustafsson et al., 2012).

Changes in the Baltic Sea ecosystem affect the ecosystem services which generate benefits to human societies. To understand how degradation can be tackled it is necessary to identify all ecosystem services and their interconnections and the conceptual framework set out by Fisher et al (2009) can help to reflect this complexity. It distinguishes between ecosystem structure and basic processes, intermediate services, final services and benefits. It also helps to avoid a double counting error when services are valued in monetary terms. Figure 2 identifies the important ecosystem services of the Baltic Sea and shows, as an example, how the final ecosystem service and 
benefit of food (in terms of fish landings) depends on many intermediate ecosystem services and processes, such as habitat, food webs, nutrient buffering, resilience etc. ${ }^{2}$

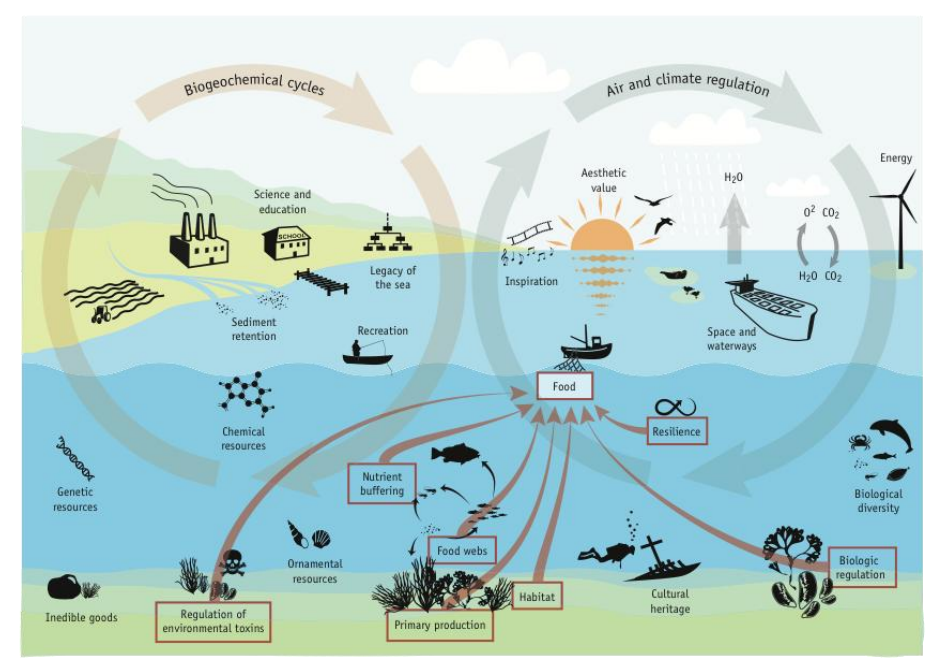

Figure 2. Ecosystem services of the Baltic Sea. Underlying ecosystem services important for fish as food are marked with yellow arrows and illustrate linkages between different ecosystem services and benefits. (SwAM ; 2013)

There are interdependencies between environmental state changes, impacts and policy responses. For example, oil spills and the consequences of invasive species may reduce benefits, such as the recreational benefits, obtained by mitigating eutrophication (Hyytiäinen \& Huhtala, 2014). The presence of hazardous substances influences the quality and value of fish, and marine litter reduces recreational values. Furthermore, there is a dynamic interplay of different pressures and the activities and drivers which cause them. This in turn leads to a change of the state of the sea and its impact on the provision of ecosystem services. Several different plausible future scenarios for the Baltic Sea are possible depending on a combination of what prevention and mitigation measures are adopted, and how drivers, activities and pressures over which the Baltic Sea countries have limited control are managed (e.g. climate, world economy, and global population). Therefore, the precise nature of the change process is subject to uncertainty as is the need for and efficacy of necessary amelioration measures in terms of the social costs and benefits of reaching a good environmental status (e.g. Borja et al., 2013).

\subsection{The governing system}

Global and regional agreements, EU directives and national laws as well as hierarchies of administrative bodies including departments, ministries, agencies, etc., all affect and complicate the management of marine environments, including the Baltic Sea (Boyes \& Elliott, 2014, 2015). Hence, the regional environmental governance of the Baltic Sea ecosystem is a fragmented web of national, European, and international governance (Gilek et al., 2011; Hassler, 2011; Karlsson et al., 2011; Kern, 2011). However, with the EU-inclusion of all littoral Baltic Sea countries except for Russia, this governance is

\footnotetext{
${ }^{2}$ Here resilience is defined as the ability to bounce back from the adverse effects of stressors, in itself an inherent property of a healthy ecosystem (e.g. Elliott et al., 2007; Tett et al., 2013).
} 
becoming more harmonised although the implementation of the EU directives and international agreements remains an on-going process.

Some of the agreements, directives and laws set targets for the desired state of the sea either now or in the future (e.g. the HELCOM Baltic Sea Action Plan (BSAP) and the Marine Strategy Framework Directive (MSFD)), whereas others target the sources behind the problems (e.g. EU Common Agricultural Policy (CAP), EU Common Fishery Policy (CFP), EU Urban Waste-water Treatment (UWWTD) and Nitrates Directive, MARPOL, IMO:s Ballast Water Management Convention (BWMC)) (Boyes \& Elliott 2014). Some of these are designed to have a direct effect on the marine environment but others (e.g. EU CAP) can have an indirect impact, positive or negative, on the state of the environment. This highlights the risk of 'regulatory failure' when governance regimes evolving over substantial periods gain redundancy and have multiple policy goals and objectives, some of which are not well co-ordinated (Turner et al., 1996). This emphasizes the need for horizontal and vertical integration of governance (Elliott, 2014).

With time, the EU Directives have moved from being sectoral targeting drivers (e.g. controlling dangerous substances and urban wastewaters) to becoming more holistic targeting state (e.g. the Water Framework Directive (WFD), the Marine Strategy Framework Directive (MSFD) and the Maritime Spatial Planning Directive) (Apitz et al., 2006; Boyes and Elliott, 2014).

The Helsinki Commission for the Baltic Marine Environment Protection (HELCOM) has played a predominant role in coordinating the environmental assessment and management of the Baltic Sea drainage area (Valman, 2013). In 2007 the HELCOM Baltic Sea Action Plan (BSAP) was signed by the governments of the contracting states under the Helsinki Convention, containing a core objective of restoring good environmental status in the Baltic Sea by the year 2021. The BSAP addresses as its priority biodiversity conservation, hazardous substances, shipping and eutrophication by using the holistic Ecosystem Approach to management to achieve the objectives.

The aim of the European Union Marine Strategy Framework Directive (EU MSFD) is to achieve Good Environmental Status (GES) of EU marine waters by 2020 and to protect the resource base upon which marine-related economic and social activities depend (Borja et al., 2013). It has been suggested that the MSFD is based for its implementation on the regional conventions, such as the BSAP, to achieve the Good Environmental Status objective (HELCOM, 2007; Long, 2011). In fact, the BSAP has been suggested as a pilot project for the MSFD (Backer et al., 2010) to ensure that GES is achieved and thus the Baltic reaches the overall aim of a healthy, safe, productive and diverse sea (Borja et al., 2013; Tett et al., 2013).

\section{Ecosystem complexity and management - the DPSIR framework}

To integrate and structure the information of both the system to be governed as well as the governing system the DPSIR (Drivers-Pressures-State-Impact-Response) scoping framework is often used (OECD, 1993; EEA, 1995; Turner et al., 1998; Gari et al., 2015), although anomalies in the DPSIR framework have now been updated to include some 
clarifying parameters in the new DAPSI(W)R(M) framework (pronounced 'dapsiworm', capitalised and in bold below) (Wolanski \& Elliott, 2015; Elliott, et al, submitted).

Within this framework, each of the main societal Drivers, which cover the basic human needs such as the need for food or recreation, requires human Activities, such as agriculture or tourism, to satisfy those needs, and these in turn lead to several Pressures such as sediment resuspension by trawling, increased polluting inputs, etc. Each of those Pressures are mechanisms which then in turn lead to several State changes, which in turn can have an Impact (on the societal Welfare). For example, change in the state of the fish populations providing the available stock will ultimately impact the ability of the fishing sector and thereby the welfare of fishermen.

Accordingly, those pressures, state changes and impacts require a Response(which are often defined in EU Directives as Measures) which if successful will ultimately prevent the Drivers and Pressures from causing State changes and Impacts (Atkins et al., 2011; Wolanski and Elliott, 2015; Elliott et al, submitted). In turn, those Responses and Measures include prevention and mitigation initiatives which are required to cover many aspects, the so-called 10-tenets. Those 10 -tenets indicate that successful and sustainable management requires actions which are: ecologically sustainable, economically viable, technologically feasible, socially desirable/tolerable, legally permissible, administratively achievable, politically expedient, ethically defensible (morally correct), culturally inclusive and effectively communicable (Elliott, 2013; Barnard and Elliott, 2015).

By using an integrated version of the DAPSI(W)R(M) scoping framework it is possible to identify more holistic management strategies that are capable of addressing the linkages between different environmental problems and their drivers and pressures (Atkins et al., 2011; Cooper 2012).

\subsection{Establishing targets for the State -capturing the system to be governed}

Each of the major environmental problems in the Baltic has its own DAPSI(W)R(M) cycle. As shown in Figure 3 these cycles can be linked and nested within a system to provide a more holistic view of the complexity of the state of the marine environment. The nested cycles for the different drivers (the need for foods, transport, living space, etc) constitute endogenic managed pressures (EnMP) onto which are superimposed the effects of Exogenic Unmanaged Pressures (ExUP) (Elliott 2011). Figure 3 reflects the main concerns in the Baltic emanating from the Drivers - eutrophication resulting from food production and urban areas; invasive species and oil spills emanating from transport; overfishing emanating from food production, and hazardous substances emanating from industrial production. 


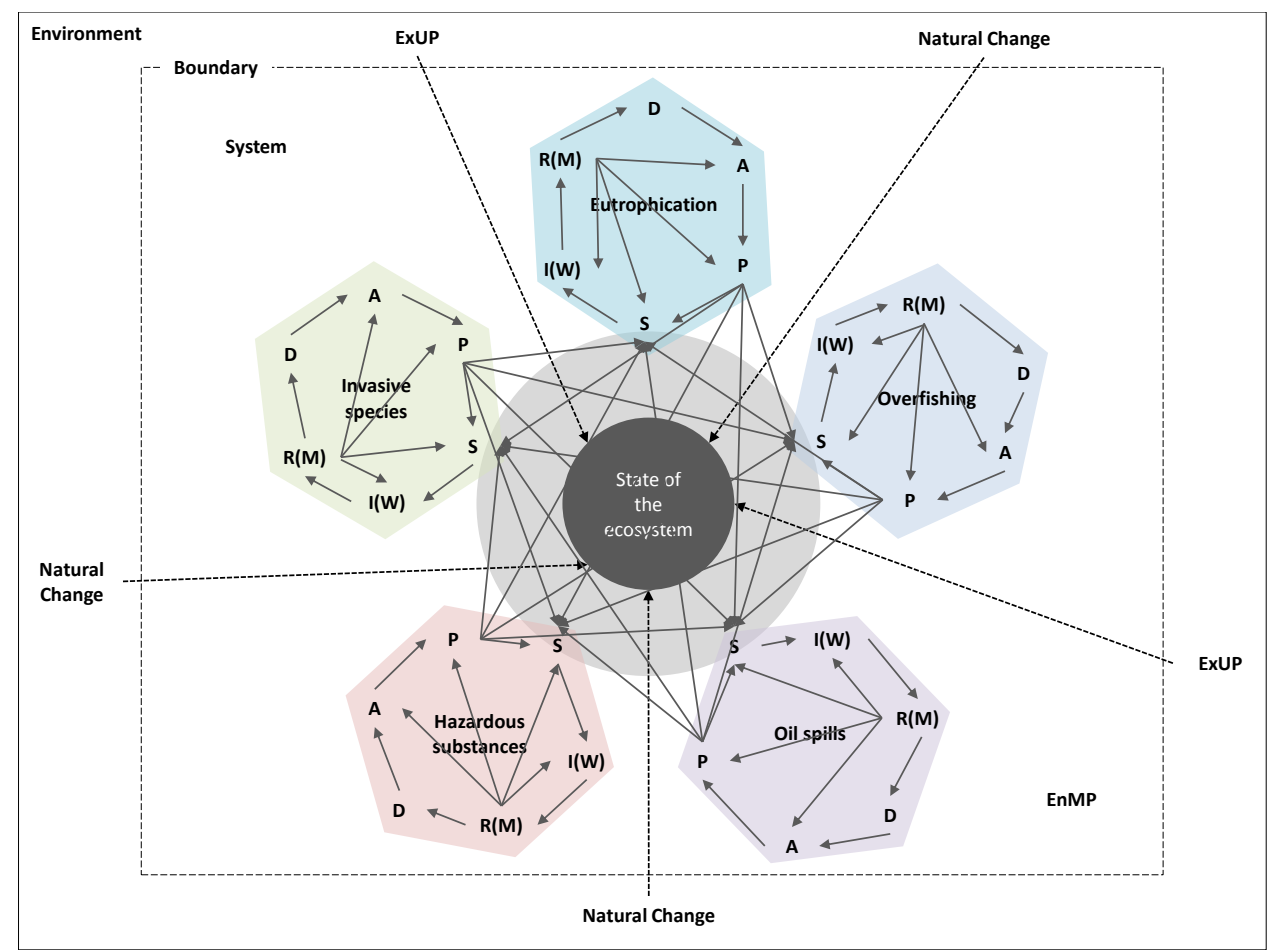

Figure 3. A nested DAPSI(W)R(M) framework for the ecosystem approach illustrating the complexity of the "system-to-be-governed". (Modified from Atkins et al. 2011; Elliott, et al, submitted)

The Impact on human well-being of a certain State change is determined by the supply of ecosystem services related to that State change. Having decided on the ecosystem state capable of providing the desired level of ecosystem services, it is possible to identify necessary restrictions to mitigate Pressures such as nutrient loads, fishing effort, risk of oil spills and invasive species. In that way a range of relevant environmental problems, as well as the interactions between them, are captured. As described in section 2.2 many targets are actually described in terms of state (e.g. MSFD, WFD) hence reinforcing the importance of State change in the DAPSI(W)R(M) framework.

By focusing on the State change of the ecosystem, as illustrated in Figure 3, a more holistic ecosystem approach can be achieved. This approach entails understanding the state of the marine ecosystem and its fundamental processes and the change due to the pressures resulting from activities. Here, ecosystem services connect the changing ecosystem state $(\mathrm{S})$ with human wellbeing through a range of ecosystem services that generate societal benefits $(\mathrm{I}(\mathrm{W})) .^{3}$

\subsection{Integrated policy response - the governing system}

The policy Responses to the environmental problems also need to be integrated, due to their potential interaction and additive effects on the system state. Therefore the whole DAPSI(W)R(M) framework and its linkages should be taken into consideration when developing policy responses aimed at managing the problems. By using the 10-tenets as

\footnotetext{
3 The Ecosystem Approach, enshrined in the 12 principles of the UN Convention on Biological Diversity, can be summarised as an ability for the management of an area to protect and maintain the natural structure and functioning of the ecosystem while at the same time support ecosystem services from which societal benefits can be obtained (Elliott, 2011)
} 
a means of framing the responses to the effects of human actions, the DAPSI(W)R(M) framework provides an adaptive management pathway (sensu Wise et al 2014). This then includes all aspects of society's ability to respond using both bottom-up processes, as the demands of stakeholders, and top-down approaches, from European and regional governance. Of course, those aspects of response are all both complicated and contain large uncertainties which increase with the length of projection (Haasnoot et al 2013).

As indicated by Figure 3, all sectoral elements each produce a state change of which their sum total is the current state of the Baltic. By rotating the sectoral elements to combine all the R(M) (Response leading to Measures) components (sensu Atkins et al., 2011; Elliott et al, submitted) the need for an integrated response is illustrated in Figure 4 , implying that to minimise the State change and achieve the desired state all responses to control the different activities (agriculture, fishing, navigation etc.) should be coordinated. Each environmental problem needs to be addressed by a separate management strategy $(\mathrm{R}(\mathrm{M})$ ), but there is also a need to integrate these into an integrated management plan. For example, the nutrient load causing eutrophication also changes the state of the fish stock, so any integrated management plan needs to take into consideration cumulative effects of the nutrient load.

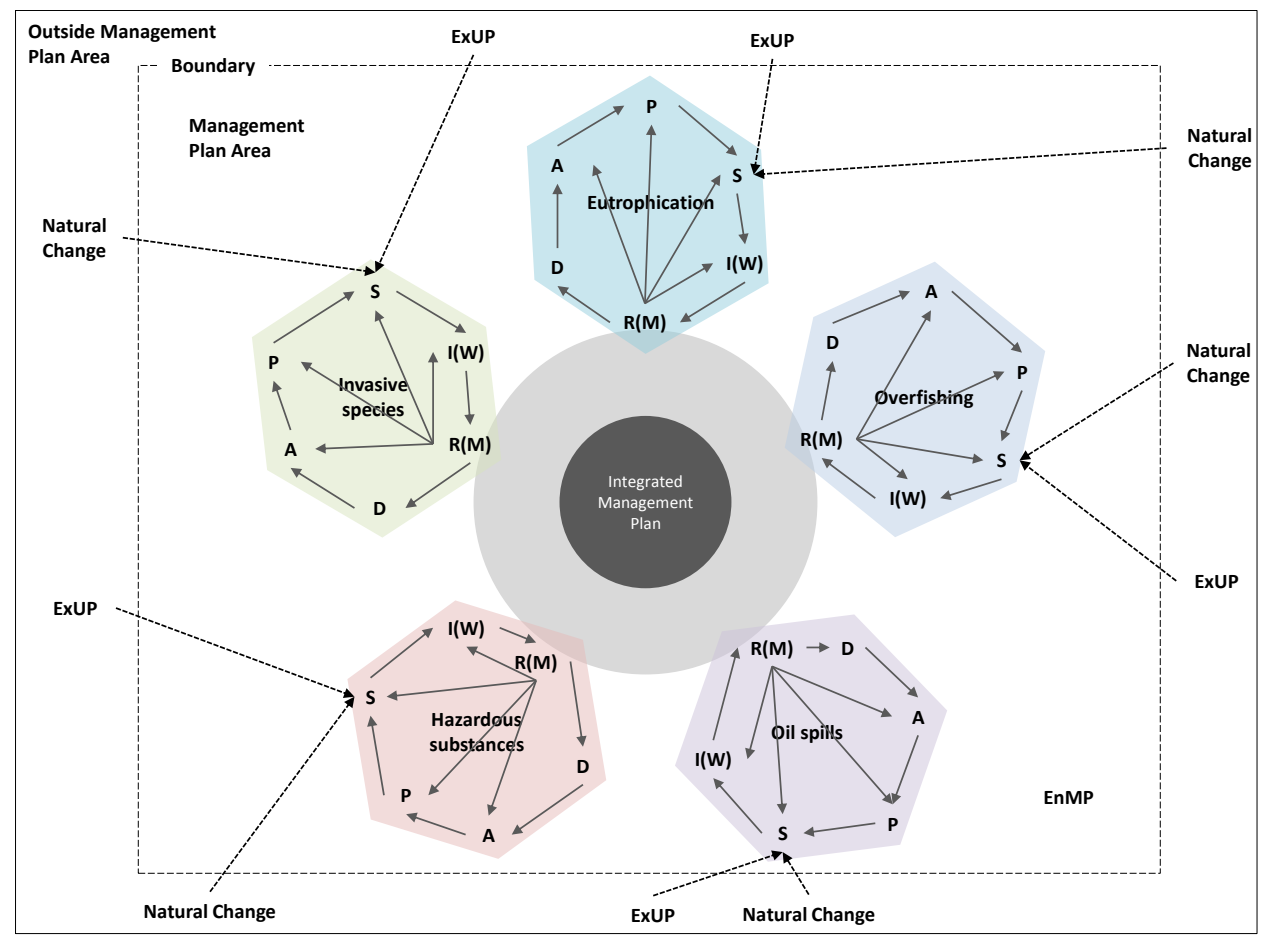

Figure 4. Integrated management of complexity; natural change refers to the normal physico-chemical and biological factors causing a change in the system which are not primarily the results of human actions; other abbreviations are given in the text. (Modified from Atkins et al. 2011; Elliott, et al, submitted)

As shown in Figures 3 and 4, Endogenic managed pressures operate inside an area of influence, such as the Baltic Sea Region, and hence management has some control over the causes and consequences, whereas governance and practical management also have to be able to cope with the 'exogenic unmanaged pressures', i.e. those aspects operating from outside a system, such as climate change, and which require coordinated 
international action (Elliott, 2011). Management at a local or regional scale is most often focused on adaptation to the consequences of exogenic change (Elliott, 2011). However, categorising a pressure as endogenic or exogenic depends on the area being managed. From a single nation perspective nitrate run-off from catchments outside its national borders constitutes an exogenic pressure, which can only be managed reactively. However, if the whole catchment area can be addressed through international agreement these pressures become endogenic and, both causes and consequences are tackled. This occurs in the implementation of the EU Water Framework Directives where all parts of the catchment are in EU states. In the case of the Baltic Sea, however, one major part lies in Russia, and therefore outside the WFD jurisdiction.

Given the complexity of the marine ecosystem to be managed, once the main parameters of the environmental problem set have been identified and as far as is feasible analysed, a policy analysis process has to be undertaken. There are many studies which detail the ecological changes in the Baltic system whereas now there is an increasing need to consider also the economic repercussions and the solutions to those changes. The DAPSI(W)R(M) framework provides an illustration of the components required for a holistic description of the problems and interconnections. However when Response decisions (R(M)) have to be made, the socio-economic impacts of different options of reaching and changing a certain state $(S)$ have to be addressed. Hence it is emphasised that the management of the system has to encompass and balance the socio-economic demands on the system while ensuring protection of the natural system. This suggests a need for a policy appraisal approach having the capacity to take such complexities into account. The one such approach for collating, analysing and presenting a more robust evidence base is the 'Balance sheet' approach (BSA) (Turner, 2007; UKNEA FO 2014; Turner and Schaafsma, 2015; Turner, 2016). The BSA process, methods and tools are compatible with adaptive management and its flexible 'learning by doing' philosophy. Recent applications include the 'Dynamic Adaptive policy Pathways' approach which combines a stepwise construction of a basic plan with contingency planning as new information accrues over time. Within this policy approach a 'pathways' focus is emphasised which addresses the sequencing of actions over time and seeks to highlight potential lock-in and path dependency issues (Kwadijk et al 2010; Haasnoot et al 2013). In later sections we compute the costs associated with a range of abatement measures necessary in order to reach Good Environmental Status (as required under the EU Marine Strategy Framework Directive) for the Baltic. These measures are foundations for the policy pathway and by and large represent 'no-regrets' actions.

\section{A decision support tool - the balance sheets approach}

The Balance Sheet Approach (BSA) described below captures the consequences of different Responses and their management Measures (costs, benefits, distributional effects, long-term effects etc.) with regard to Drivers, State change, Impact on human Welfare, etc. The BSA is both a process and a tool and can be applied sequentially according to the policy context and levels of complexity and uncertainty. 
In the BSA three types of complementary assessments (balance sheets) are envisaged to give guidance for steering a reasonably objective course through uncertain and often highly'contested' policy contexts (Figure 5).

1

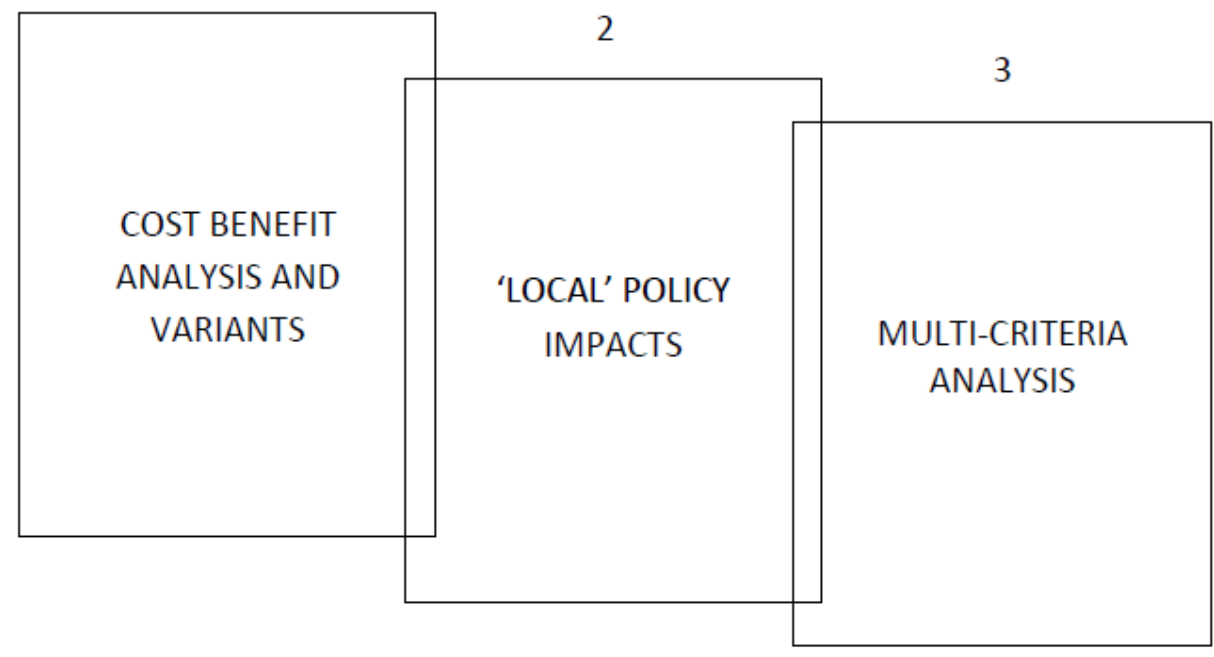

'SIMPLE'

'COMPLEX'

ENVIRONMENTAL

ENVIRONMENTAL

CONTEXT

CONTEXT

Figure 5. 'Balance sheets' approach. Adapted from (UKNEAFO 2014)

As the simplified figure illustrates, the appraisal may start (sheet 1) with an efficiencybased cost-benefit analysis and environmental impact assessment, but is then supplemented by an explicit focus on the winners and losers (distributional analysis) in any given policy context (sheet 2) and further wider ethical and policy consequences (sheet 3).

Decision support tools, incorporated into the Responses in the DAPSI(W)R(M) framework, such as the economic Cost-Benefit Analysis (CBA) of sheet 1, are important for informing about relevant trade-offs from an economic efficiency perspective. However, complementary approaches are needed in order to broaden the scope and tackle the multi-dimensionality of decision making (Söderqvist et al., 2015).

Sheet 2 highlights financial and social impacts on sectors through to households, often experienced at the regional/local spatial scale, such as loss of employment due to fisheries closure or loss of productivity, with possible community identity and culture losses. In the Marine Strategy Framework Directive (MSFD) terms we are now shifting 
from an economic appraisal into a wider social appraisal which includes non-monetary values associated with cultural/symbolic ecosystem services. These contexts often raise issues of 'compensation' and the need for tools to enable such action, or the need for other enabling policy instruments that can ensure that polluters take action.

The risk of threshold effects and regime shifts with uncertain but potentially significant future damage costs also raises ethical questions and makes the more 'precautionary' and safe operating space approach more compelling. CBA results need to be treated with caution in the presence of non-linear and non-marginal risk since they are based on individual preferences and most reliable for marginal changes of costs and benefits. In such complex contexts, it is important to undertake holistic long-term analysis including also assessment methods other than CBA. The third 'balance sheet' incorporates these concepts and may require the use of multi-criteria analysis decision tools to help in the appraisal process. These tools can include more deliberative forms of policy option evaluation and may include analysis of values that goes beyond values based on individual preferences, and are driven by a collective or shared responsibility for societal well-being, so called 'shared' values (Fish et al., 2011; Spash 2007, 2008).

One way to cope with future uncertainty is to deploy scenario analysis as shown in the Millennium Ecosystem Assessment (MEA, 2005). Scenarios can help to put approximate 'bounds' around future uncertainties and thereby contribute to a decision support system based on the principles of adaptive management.

Overall, the aim in the BSA is not to aggregate the results of each overlapping balance sheet but to present policymakers with an evidence base made of a suite of complementary findings in as transparent a way as possible, and to encourage a move away from short term expediency towards a longer term perspective. The more complex or contested policy context, the more 'balance sheet' evidence will need to be deployed.

\section{Applying BSA to the Baltic Sea}

In this section two empirical studies are presented providing decision support information regarding the Baltic Sea relevant for the three BSA sheets. These studies can illustrate ways to provide decision makers with information needed according to the theoretical frameworks and tools.

The BalticSTERN CBA initiative, described below, provides a full-scale analysis (BSA sheet 1) of the eutrophication problem. ${ }^{4}$ It also provides information on cross-country distributional consequences in line with the second BSA sheet. The CBA component includes non-use values, and a case study on shared values was also undertaken. This type of plural values evidence is what is envisaged in the third sheet of a BSA. The BalticSTERN assessments are based on scenarios linked to the development of eutrophication in the Baltic Sea.

\footnotetext{
4 BalticSTERN is an international research network with partners in all nine Baltic Sea countries. The scientists combine ecological and economic models with the purpose of doing cost-benefit analysis regarding the environmental problems of the Baltic Sea and give guidance toward cost-effective measures.
} 
The second study of Niiranen et al. (2013) encompasses fishing effort impacts and climate effects, illustrating the need for long-term and holistic perspectives covering dynamic processes and effects of both endogenic and exogenic pressures.

\subsection{BalticSTERN cost-benefit analyses of eutrophication mitigation}

Within the Baltic Sea Action Plan (BSAP), the nine countries surrounding the Baltic Sea have agreed to reduce their nutrient loads by a specific amount for each country

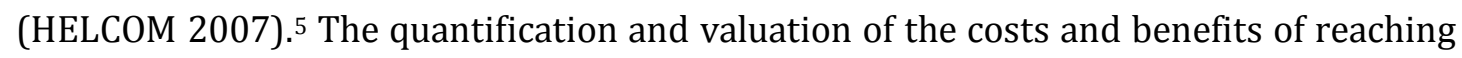
these nutrient load targets was a key objective of recent studies undertaken by the international research network BalticSTERN, with partners in all littoral countries around the Baltic Sea (SWAM , 2013). This research has indicated that reaching the BSAP targets with respect to eutrophication will, in aggregate, generate net welfare gains.

As a first step towards capturing the benefits of reaching the BSAP, a study, BalticSurvey, was undertaken in 2010 (Ahtiainen et al., 2013) examining the public use of the Baltic Sea, and people's attitudes towards the marine environment and towards responsibilities for improving the environment. The survey showed that some $80 \%$ of the people living in the Baltic Sea region have spent leisure time related to the Sea and that many (ranging from approximately 40 to $75 \%$ of the respondents in the different countries) were concerned about the environmental state of the Baltic Sea.

Based on BalticSurvey, an economic valuation survey BalticSUN (Ahtiainen et al., 2012; Ahtiainen et al., 2014) was performed in 2011 investigating the benefits of reaching the BSAP nutrient reduction targets. For the first time, people in all nine countries around the Baltic Sea were simultaneously surveyed about their willingness to pay for reduced eutrophication of the Sea. The study used the contingent valuation method, one of the few economic valuation methods that can capture both use and non-use values (Carson \& Hanemann 2005). Non-use values refer to values not connected to the use of the Sea, such as the value of having a healthy Sea to pass on to future generations, or the value of knowing that the Sea will recover from its environmental problems.

A so-called Business-As-Usual (BAU) long-term (2050) scenario was described, in which no additional actions were taken to reach the BSAP nutrient reduction targets. This scenario implies a state of the Baltic Sea characterized by frequent algae blooms, hypoxia and diminishing cod stocks. Thereafter a scenario in which the BSAP reduction targets were met was described, leading to an improved ecological state of the Baltic Sea in 2050 in terms of less algae blooms and hypoxia. The two scenarios are illustrated in figure 6.

Business-As-Usual (Inaction) Implementation of BSAP

5 The BSAP targets were to some extent revised at the HELCOM ministerial meeting 2013 (HELCOM 2013). 


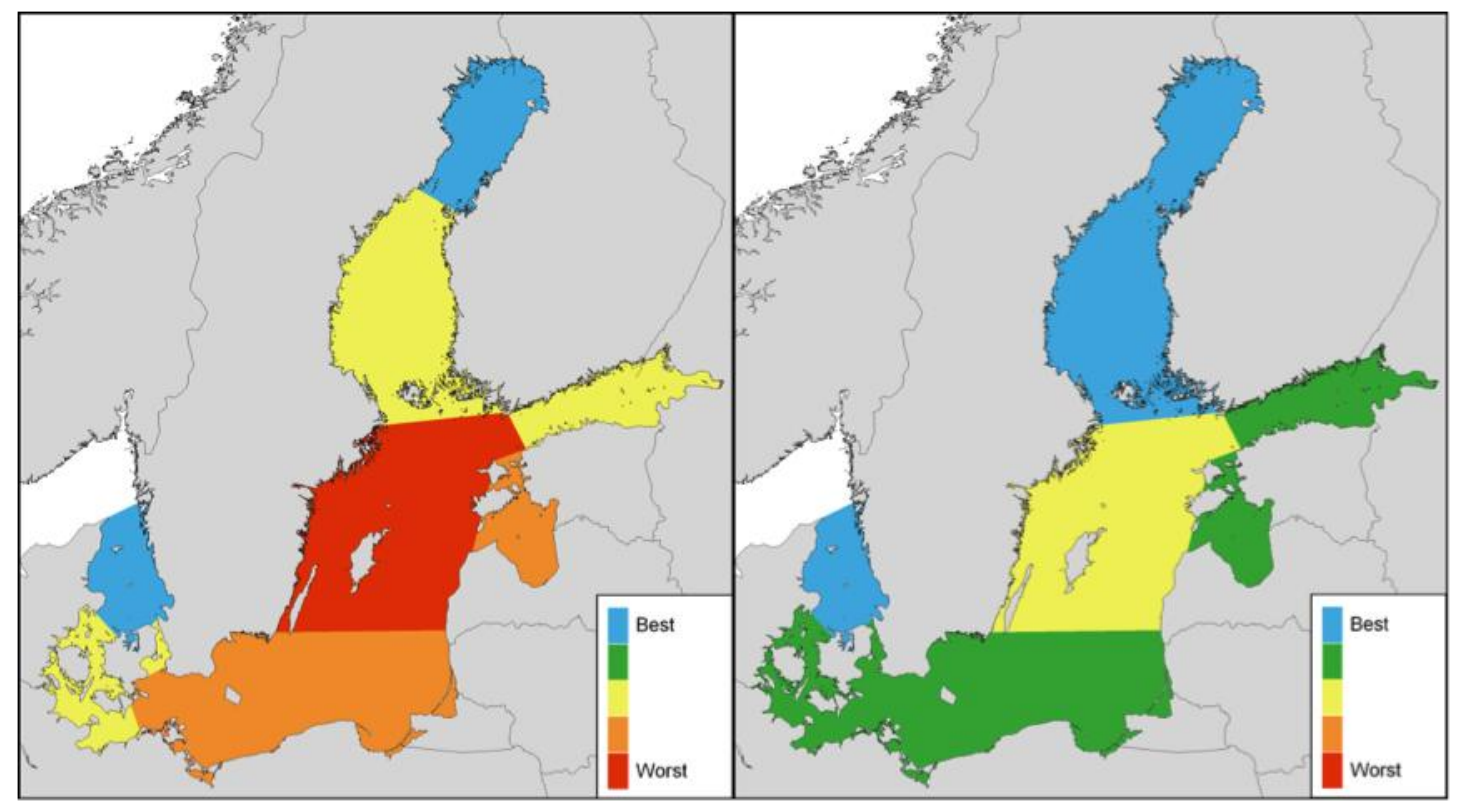

Figure 6. Maps showing eutrophication of the Baltic Sea in a Business-As-Usual scenario (left) and in a scenario where the Baltic Sea Action Plan is fulfilled (right). (Ahtiainen et al. 2014)

Ahtiainen et al. (2014) showed that most of the respondents are willing to pay for an improvement of the environmental state. Total benefits were estimated to be about 4 $600 \mathrm{M} €$ annually for reaching the BSAP goals by 2050 .

The costs of reaching the BSAP sea basin targets via a cost-effective allocation of abatement measures were estimated to be around $2300 \mathrm{M} €$ annually. The costs of reaching the targets according to the BSAP country quotas, on the other hand, were estimated to be $2800 \mathrm{M} €$ annually (Hyytiäinen et al., 2015) ${ }^{6}$. The estimated costs were based on costs and effectiveness of several abatement measures in agriculture and wastewater treatment that can be implemented in different parts of the catchment area. $^{7}$

In line with BSA, table 1 illustrates the way in which the benefits and costs would be distributed between the countries, under a cost-effective reduction of nutrients, to the different sea basins. ${ }^{8}$ This shows that even though the total welfare gain amounts to about $2300 \mathrm{M} €$ annually, some countries will experience costs that exceed their benefits, under the assumption that each country is financially responsible for the

\footnotetext{
6 The discount rate of $3.5 \%$ was used for both costs and benefits throughout the calculations. A majority of the total cost comes from abatement measures that have no investment costs, such as reduction in fertilizer use, use of catch crops and reduction in detergent use. Most benefits accrue during the forthcoming decades.

7 The measures were reduction of fertilizers, reduction of cattle, pig or poultry, cultivation of catch crops, constructing sedimentation ponds, restoring wetlands, reducing phosphate in detergents and improving wastewater treatment. A catchment model was used to determine a cost-effective combination of measures to reduce the overall loading below the maximum allowable inputs of nitrogen and phosphorus as defined in the BSAP (Ahlvik et al., 2014)

${ }^{8}$ Some of the measures behind the cost estimates will, apart from the effect on the Baltic Sea, also have positive effects on the state of inland waters within the Baltic Sea drainage area, and also to some extent on the North Sea. These effects are likely to generate additional benefits beyond those considered in the study, implying even larger benefits as a result of the BSAP than the ones captured in the BalticSUN study. It is also likely that the estimated total cost is an overestimation due to the limited number of abatement measures, coarse spatial resolution and exclusion of any possible new technological development. As the benefits are probably underestimated and the costs are likely to be overestimated, the conclusion that implementing the Baltic Sea Action Plan would generate net welfare gains can be regarded as robust. (SwAM, 2013; Hyytiäinen et al., 2015)
} 
measures taken within the country. However, the table does not illustrate the distribution of costs between different stakeholders within the countries (e.g. agriculture, households, industry).

Table 1. Distribution of benefits and costs between countries under a cost-effective solution (Hyytiäinen et al. 2015).

\begin{tabular}{|c|c|c|c|c|}
\hline Country & $\begin{array}{l}\text { Benefits } \\
\text { M€/year }\end{array}$ & $\begin{array}{l}\text { Costs } \\
\text { M€/year }\end{array}$ & $\begin{array}{l}\text { Net benefits } \\
\text { without } \\
\text { transfers } \\
\text { M€/year }\end{array}$ & $\begin{array}{l}\text { Benefit/Cost } \\
\text { ratio }\end{array}$ \\
\hline Denmark & 265 & 630 & -365 & 0.4 \\
\hline Estonia & 23 & 78 & -55 & 0.3 \\
\hline Finland & 263 & 23 & 240 & 11 \\
\hline Germany & 2271 & 480 & 1791 & 4.7 \\
\hline Latvia & 8 & 85 & -77 & 0.1 \\
\hline Lithuania & 14 & 101 & -87 & 0.1 \\
\hline Poland & 236 & 544 & -308 & 0.4 \\
\hline Russia & 308 & 105 & 203 & 2.9 \\
\hline Sweden & 1237 & 290 & 947 & 4.3 \\
\hline Total & 4625 & 2336 & 2289 & 2.0 \\
\hline
\end{tabular}

BalticSTERN research also carried out a case study indicating the existence of shared values regarding the Baltic Sea resources and services provided by the sea (Cole, 2013). These values (sheet 3 of the BSA) are distinct from the individual preference-based values captured by the BalticSUN study.

In the BalticSUN study, two future possible scenarios of the Baltic Sea at 2050 were described to survey respondents. The two scenarios represent the same global scenario, which agrees with a best-case scenario with no expected large-scale increases in the drivers and activities controlling the nutrient load (e.g. agricultural production) to the Baltic Sea. Prognoses regarding agricultural production ten years ahead were included in the modelling but indicated no significant changes on the long-term aggregate level. The BalticSUN scenarios did not include climate effects as they were estimated to be minor in the time perspective chosen (40 years). Recent research however indicates that climate-induced effects will be seen earlier than previously thought. If a global scenario including earlier climate change effects had been used in the CBA, the costs as well as benefits of reaching the BSAP targets would differ. The costs of reaching the BSAP basin targets would be higher as more prevention and mitigation measures would be required. However, the difference between the two scenarios (with and without implementing the BSAP) illustrated in the BalticSUN survey, would be larger, suggesting that the benefits of implementing the BSAP could also be larger.

New challenges to the achievement of 'good quality status' in the Baltic Sea are also emerging from other unmanaged exogenic pressures at the global scale. The development of drivers, activities and pressures affecting the state of the Baltic Sea is to a large extent dependent on global trends. For example, future changes in the size and 
intensification of agricultural production and global demand for agricultural products will influence the potential nutrient load to the Baltic Sea. These changes are largely driven by world market price fluctuations and trends. Furthermore, global climate change will have direct (e.g. increased nutrient run-off and prolonged growth period of cyanobacteria) as well as indirect effects (e.g. intensified agriculture, change of cultivated crops) on the nutrient load and the environmental state of the Baltic Sea (Elliott, et al., 2015; BACC, 2008). Thus, it is important to consider how the global drivers might evolve when developing future scenarios for the Baltic Sea. The scenarios presented in 5.2 below provide information about possible future changes not captured in the BalticSTERN CBA.

\subsection{Scenarios for the Baltic Sea}

Climate change is emerging as a potentially dominant driving force of pressure and change on the Baltic Sea (IPCC AR5 WG1 2013; WG II 2014) and has large repercussions for the ability to meet the status required under, for example, the MSFD (Elliott et al., 2015). In particular, baselines and reference conditions set now and against which management measures may be judged will have to be changed as the result of climate change. Recent projections indicate that climate change may cause a warmer and less saline Baltic Sea than ever measured (measurements available since 1850), and that the climate-induced effects will be seen earlier than previously thought (Meier et al., 2012a). Further, modelling studies show that in the 'best-case' nutrient management scenario (a scenario where the Baltic Sea Action Plan (BSAP) nutrient reduction targets were achieved) the phytoplankton production of the open Central Baltic Sea is likely to remain at current levels indicating that projected climate change may work against the expected outcome of nutrient load reductions. In a 'worst-case' scenario, i.e., substantial increases in nutrient loads combined with change in future climate, increase in hypoxia as well as in summer algae blooms are indicated (Meier et al. 2012b). Other long-term development scenarios envisage significant increases in activities such as agricultural production and sea and land transport (see e.g. Agrimonde, 2009; Öborn et al., 2011; WWF, 2012).

Niiranen et al. (2013) used a food web modelling approach to study how the two future nutrient load scenarios from Meier et al. (2012b), in combination with two cod fishing scenarios (past intensive fishing and precautionary approach), would affect cod stock and phytoplankton biomass. Figure 7a shows that the cod stock is projected to be close to extinction in the worst-case scenario with high fishing pressure on cod and increasing nutrient loads. In contrast, the best-case scenario, with decreased fishing pressure on cod (following the EU cod recovery plan, EC 2007) and fulfilment of the BSAP targets regarding nutrient loads, was projected to result in an improvement in cod stock compared to present conditions. Nevertheless, due to climate change causing a decrease in salinity and worsening oxygen conditions, a new decrease is projected in the cod biomass towards the end of the century. The phytoplankton biomass projections follow the trends found in Meier et al. (2012b) independent of the cod fishing scenarios (Figure $7 \mathrm{~b})$. The future food web model projections of cod and phytoplankton include more extreme values than projected for the past reference period (1974-2006) (Figure 7, Niiranen et al. 2013). Hence, the risk for unpredicted and unanticipated ecological repercussions, including regime shifts, is present in both future scenarios. 
a)

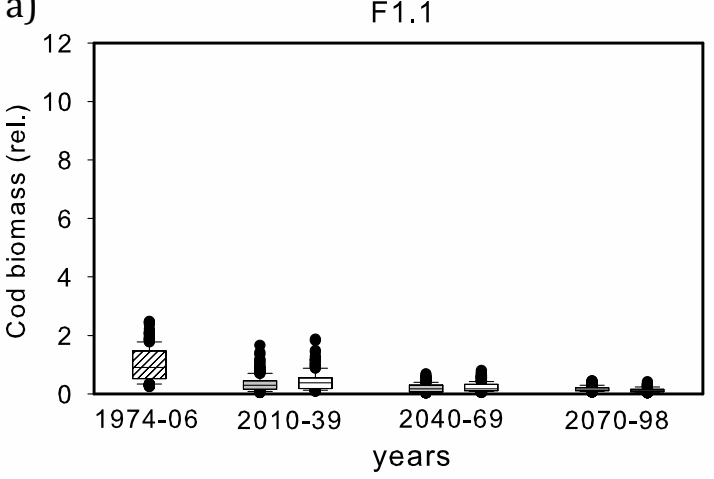

b)

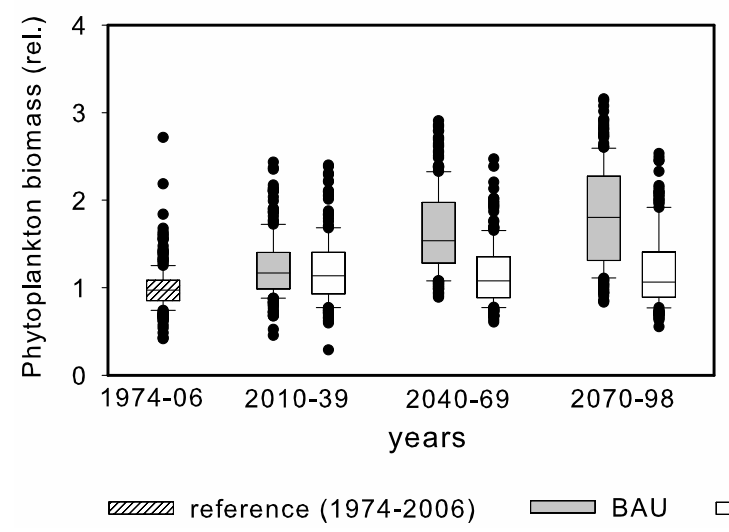

F 0.3

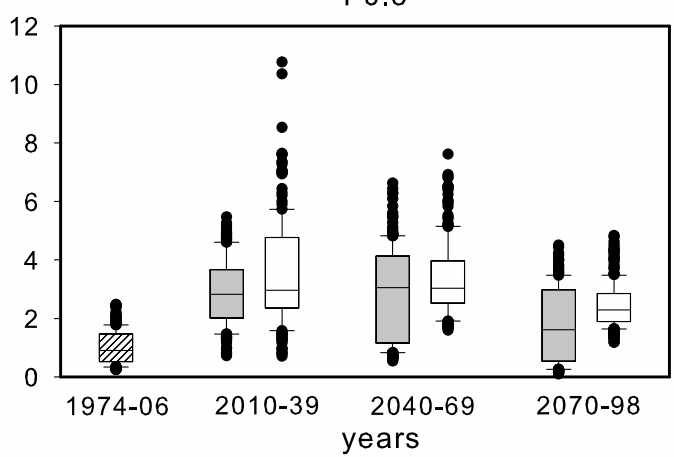

Figure 7. Future change in the a) cod and b) phytoplankton biomass as projected by the BaltProWeb food web model in combined nutrient load (BAU:high, BSAP:low) - cod fishing (F1.1:high, F0.3:low) scenarios. The box and whisker plots indicate the median, as well as $25 \%$ and $75 \%$ quartiles and comprise biomass projections from the food web model when forced with the output from three regional biogeochemical models (BALTSEM, ERGOM and RCO-SCOBI) that were all driven by three future climate scenarios (based on IPCC greenhouse gas emission scenario A2 and two realizations of scenario A1B). All values are presented as a relative change (rel) from the reference (average of years 1974-2006) conditions; base model units are t wet weight $\mathrm{km}^{-2}$. (Modified from Niiranen et al. 2013)

In summary, the BalticSTERN CBA has delivered a full-scale analysis regarding eutrophication for the first BSA sheet. There is also information on distributional causes and effects between countries giving some input into further in-country analysis in line with the second sheet. The CBA includes non-use values, and a case study has revealed the existence of shared values. The need to examine and present this type of plural values evidence is what is envisaged in the third sheet of a BSA. The empirical studies of Niiranen et al. (2013) provides further input to Sheet 3 of the BSA, in that it broadens the perspectives of possible future changes regarding the state of the Baltic Sea.

\section{Management implications}

Many preconditions for ameliorative actions towards an improved state of the Baltic Sea are in place on EU level and in many Baltic Sea countries. As described in section 2 there is sufficient scientific consensus regarding the problems and their origin. It is also shown that political frameworks are in place. That public awareness and support for action exists was clear from the surveys made within BalticSTERN (Ahtiainen et al., 
2013; SwAM , 2013). Possible measures that could be implemented in order to meet the environmental objectives have been identified in a number of studies as well as within the WFD and the BSAP (see Elofsson 2010 for review). In light of the pathways approach the type and sequencing of these foundational measures is reasonably clear. In $2015 \mathrm{EU}$ Member States were required to deliver their lists for Measures required to meet Good Environmental Status under the MSFD (Elliott, et al, 2015). Therefore it is apposite to ask what more is required to reach the desired state of the Baltic Sea?

In order to answer that question it is important to make a distinction between strategic policy initiatives that provide the framework (in terms of e.g. goals, programmes of measures, allocation of responsibilities), such as the MSFD and BSAP, and enabling policy instruments that create incentives for measures to be implemented (e.g. taxes, regulation and information). Ultimately it is the enabling policy instruments of the management strategy that will be decisive for the state of the Baltic Sea and for the delivery of ecosystem services and benefits to society. The success of meeting the environmental objectives is therefore determined by the ability and will of national government to implement enabling instruments capable of meeting these objectives.

The reason why countries are not able to meet the objectives might be explained by the allocation of costs and benefits (i.e. the distributional effects illustrated in Table 1) as well as future uncertainties. When deciding on management strategies it is therefore necessary to take distributional effects into consideration (sheet 2 in the BSA) as well as future uncertainties (Sheet 3). Those two dimensions are discussed in the following.

\subsection{Management challenges linked to distributional effects}

The acceptance, and thereby success, of any management strategy is conditional upon the way in which the benefits and costs of improving the state of the Baltic Sea are distributed between different countries (see Table 1 section 5) as well as amongst different stakeholders (e.g. agriculture, shipping, industry, households).

The distribution of costs between countries is to a large degree dependent on agreements, such as the BSAP. In essence, that distribution has two aims. On the one hand, good policies should promote cost-effectiveness, that is, allocate abatement measures to countries where the marginal abatement costs are the lowest. For example, a given amount of funding may produce more benefit by putting some sewage treatment where there is none rather than upgrading an existing plant. As shown in the BalticSTERN case, a cost-effective allocation of measures would reduce total costs substantially compared to meeting the BSAP country quotas.

On the other hand, in order to create incentives for each country to participate in cooperation, costs should be distributed such that all countries can feel that they gain from nutrient abatement. This would mean allocating more costs to countries that benefit the most from reduced eutrophication. As illustrated in Table 1 there are countries where benefits clearly exceed costs but also vice versa.

The two aims do not necessarily have to be in conflict with each other as long as there exist mechanisms, such as a joint implementation mechanism or a market for tradable permits, for a country to finance abatement measures in other countries. 
Distribution of the costs across stakeholders will also depend on the type of enabling policy instrument that is used to get the required measures implemented. A tax on the polluting activity, for example, implies that it is the economic sectors responsible for the pollution that incur the financial burden, in accordance with the polluter-pays-principle (PPP). Subsidizing the required measures means that it is the national taxpayers that finally carry the burden. Under the current EU directives (described in section 2) it is, to a large degree, up to the Member States to decide on the enabling instruments to be implemented in order to reach the targets. The current degree of acceptance for different enabling policy instruments, environmental awareness, macro-economic situation and political priorities often differ across countries. This might imply that implementation plans face different prospects in terms of effective realisation in the respective countries. The distributional analysis above should thus be complemented by addressing the distributional effects that different enabling instruments would have on stakeholders within countries.

In summary the distributional effects captured in sheet 2 of the BSA provide important information when determining how a management strategy can be designed on a regional as well as a national level in order to be politically feasible.

\subsection{Management challenges linked to uncertainties and future risks}

In the Baltic Sea there are inherent challenges to management due to the long time-lags between the response being initiated and the positive changes in state (as is the case for eutrophication). In addition to this, exogenic drivers and pressures will be of increased importance for the outcome of any management strategy and may, in the case of climate change, mask any benefits of measures operating on endogenic pressures (Elliott, et al., 2015).

As illustrated in Sections 2 and 5.2, the Baltic region faces a novel set of drivers, activities and pressures (some global in scope) the outcomes of which are uncertain but potentially highly damaging and costly. A Worst Case, -Non-action BAU scenario, may imply that a large proportion of the Baltic Sea ends up in a poor or even bad state by the end of this century as a result of climate change, and increased and intensified agricultural production in the region as well as overfishing (see Section 5.2). Furthermore, although not yet fully understood, feedback mechanisms, such as remobilisation of nutrients, may enhance the risk of surpassing thresholds and may trigger the ecosystem into a state that is even worse (Nyström et al., 2012). There are risks of regime shifts and possible system collapse due to changes in the resilience of components of the system. These characteristics of contemporary environmental change pose particular challenges for the management of ecosystem services.

In summary, the management strategy required for meeting the environmental objectives might change in the future due to:

- a more rapid impact from external forces (e.g. climate change) than expected,

- interactions that are not covered by the management strategy or yet not completely understood (e.g. eutrophication-invasive species and anoxiaremobilisation of toxic substances), 
- feedback mechanisms that accelerate undesirable changes (e.g. internal loading of phosphorus) and the risk of regime shifts.

To meet these challenges there is a need for new integrated adaptive management strategies (e.g. Wise et al, 2014; Haasnoot et al, 2014). An important part towards building such strategies is to develop scenarios able to capture actions needed under different possible future outcomes. The conundrum in Baltic management, however, is that uncertainties which can be overcome when only a single country is involved (e.g. Haasnoot et al., 2013) become even greater with the complex socio-political systems in the Baltic catchment.

Monitoring the state and using models to estimate effects of actions is a given component in any management strategy. Targets might need to be revised and policy instruments strengthened as new information is obtained. Such an adaptive approach recognises that action has to be taken often in circumstances when complete knowledge is lacking.

The present state of the Baltic Sea shows that immediate action to improve the situation is needed. Regardless of how global drivers will evolve, a 'wait and see' policy is not justified and current action aimed at improving the state of the Baltic Sea based on current information is a minimum requirement. This has to be done before knowing with certainty about effects of previous action and also about what may be needed now in order to prevent serious future regime shifts.

A way to handle this dilemma is to determine what kind of actions would be needed under different scenarios and compare these with actions considered in the short-term perspective. This would provide insights into what can be identified as no regret solutions, that is, actions motivated regardless of future developments. Such an adaptive strategy will be required under the large current and future uncertainty in the social and political situation and the ability of states to implement adaptive changes (Wise et al, 2014; Haasnoot et al, 2014).

Such an analysis would also help to identify the need for actions required under the precautionary principle. Building the internal resilience of the system (e.g., by safeguarding biological diversity and reducing nutrient load) to prepare it for rising pressures and shocks from climate change and other global environmental risks is in line with the precautionary principle and should be a part of the management strategy (UNEP, 2012). In the case of the Baltic Sea this could imply action going beyond the nutrient targets of the BSAP.

In summary, a deeper sustainable management strategy may be needed to respond to possible future increase of drivers, growing evidence of external pressures, interactions and non-linear dynamics - a strategy aimed at increasing the resilience required to cope with and adapt to change.

\section{Conclusions}

This paper describes a process that could be used to achieve a sustainable stewardship of the marine environment based on the ecosystem approach. The DAPSI(W)R(M) 
framework and the BSA decision support system are suggested as vital frameworks, processes and tools to capture the information needed for a successful management. Empirical studies from the Baltic Sea have been used to illustrate the information required for such a process.

To achieve an efficient management plan for a complex marine ecosystem a holistic perspective is important. As a basis for such a process we suggest an integrated DAPSI(W)R(M) framework which enables capturing all the vital components needed to be taken into account. In this way, targets can be based on a holistic approach for the ecosystem and all environmental problems and management (response) on a more integrated approach instead of the current sectoral approach.

The described BSA support process and tool (Section 4) is capable of providing guidance on necessary considerations when deciding on measures and enabling policy instruments. It is a tool for a successive analysis of costs and benefits of potential response, distributional effects and consideration of uncertainties and ethical perspectives. The empirical studies verify the importance of including all these perspectives of the BSA.

The empirical Baltic Sea study described in section 5.1 shows that it is possible to undertake cost-benefit analyses on a regional scale, thus providing opportunities for more cost-effective solutions and information of distributional consequences among countries.

A particular challenge is to recognise that integration between land- and sea-based sectors is no longer sufficient. As illustrated by the scenarios in section 5.2 these must now also be integrated with the rising importance of cross-scale interactions where exogenic climate change is emerging as a dominant pressure influencing all other processes, such as increasing Baltic Sea sensitivity to over-fishing and eutrophication. Due to such future uncertainties, management strategies need to be adaptive and precautionary.

Given the above, there is need for an adaptive ecosystem-based, holistic and integrated management strategy with a common vision for a sustainable transformation of the marine environment, which could safeguard ecosystem services and the benefits they provide to human societies. It is vital that a coherent and agreed package of enabling policy instruments and their sequencing within an adaptive policy pathway is in place and in accordance with the precautionary principle and the concept of safe operating space (Rockström et al., 2009).

\section{Acknowledgements}

We thank the anonymous referee for the helpful comments in improving an earlier version of the paper. We are also grateful to Berit Hasler (Aarhus University) for valuable comments during the writing process and to Daryl Burdon (IECS) for help to improve figure 3 and 4. This work has partly been funded by the Swedish Agency for Marine and Water Management. 


\section{References}

Agrimonde. 2009. Scenarios and Challenges for Feeding the World in 2050. Summary Report

Ahlvik L, Ekholm P, Hyytiäinen K, Pitkänen H, 2014. An economic-ecological model to evaluate impacts of nutrient abatement in the Baltic Sea. Environmental Modelling \& Software 55:164-175

Ahtiainen, H, J Artell, M Czajkowski, B Hasler, L Hasselström, A Huhtala, J Meyerhoff, J C R Smart, T Söderqvist, M Alemu, D Angeli, Dahlbo, K., Fleming-Lehtinen, K Hyytiäinen, A Karlõševa,Y Khaleeva, M Maar, L Martinsen, T Nõmmann, K Pakalniete, I Oskolokaite, O Ragistrina och D Semeniene. 2014. "Benefits of meeting nutrient reduction targets for the Baltic Sea - a contingent valuation study in the nine coastal states", Journal of Environmental Economics and Policy, vol 3, s 278-305.

Ahtiainen, H. Artell, J., Czajkowski, M., Hasler, B., Hasselström, L., Hyytiäinen, K., Meyerhoff, J., Smart, J. C. R., Söderqvist, T., Khaleeva, J., Ragistrina, O. \& Tuhkanen, H. 2013. Public preferences regarding use and condition of the Baltic Sea - An international comparison informing marine policy. Marine Policy 42, 20-30.

Ahtiainen, H. et al. 2012. Benefits of meeting the Baltic Sea nutrient reduction targets Combining ecological modelling and continegnt valuation in the nine littoral states. MTT Discussion Papers 1/2012. www.mtt.fi/dp/DP2012 1.pdf, MTT Agrifood Research Finland.

Apitz, S.E., Elliott, M., Fountain, M., and Galloway, T.S. 2006. European Environmental Management: Moving to an Ecosystem Approach. Integrated Environmental Assessment \& Management. 2(1) 80-85.

Atkins, J., Burdon, D., Elliott, M., Gregory, A. J. 2011. Management of the marine environment: Integrating ecosystem services and societal benefits with the DPSIR framework in a systems approach. Marine Pollution Bulletin 62: 215226

BACC Author Team 2008. Assessment of Climate Change for the Baltic Sea Basin. Springer-Verlag, Berlin, ISBN 978-3-540-72785-9.

Backer H, Leppänen J-M, Brusendorff A C, Forsius K, Stankiewicz M, Mehtonen J, Pyhälä M, Laamanen M, Paulomäki H, Vlasov N, Haaranen T 2010. HELCOM Baltic Sea Action Plan - a regional programme of measures for the marine environment based on the ecosystem approach. Marine Pollution Bulletin 60: 642-649

Barnard, S and M Elliott 2015. The 10-tenets of adaptive management and sustainability - applying an holistic framework for understanding and managing the socioecological system. Environmental Science \& Policy, 51: 181-191.

Borja, A., Elliott, M., Andersen, J.H., Cardoso, A.C., Carstensen, J., Ferreira, J.G., Heiskanen, A.-S., Marques, J.C., Neto., J., Teixeira., H., Uusitalo., L., Uyarra., M.C., Zampoukas, N. 2013. Good Environmental Status of marine ecosystems: What is it and how do we know when we have attained it? Marine Pollution Bulletin, 76: 16-27. 
Borja, A, Elliott, M, Andersen, JH, Berg, T, Carstensen, J, Halpern, BS, Heiskanen, A-S, Korpinen, S, Lowndes, JSS, Martin, G, Rodriguez-Ezpeleta, N (2016). Integrative assessment of marine systems: the Ecosystem Approach in practice. Frontiers in Marine Science March 2016 Volume 3 Article 20, doi: 10.3389/fmars.2016.00020.

Boyes, S.J. \& Elliott, M. 2014. Marine Legislation - the ultimate 'horrendogram': International Law, European Directives \& National Implementation. Marine Pollution Bulletin, 86(1-2): 39-47.

Boyes, S.J. \& Elliott, M 2015. The excessive complexity of national marine governance systems - has this decreased in England since the introduction of the Marine and Coastal Access Act 2009? Marine Policy, 51: 57-65.

Carson, R. T., Hanemann, W. M. 2005. “Contingent Valuation,” in Mäler, K. G., Vincent, J. R., ed., Handbook of Environmental Economics. Valuing Environmental changes. Vol. 2. Amsterdam: Elsevier, pp. 821-936.

Carstensen, J., J. H. Andersen, B. G. Gustafsson, and D. J. Conley. 2014. Deoxygenation of the Baltic Sea during the last century. Proceedings of the National Academy of Sciences of the United States of America 111: 5628-5633

Cole, S 2013. Shared values - Background paper. Havs- och vattenmyndighetens rapport 2013:4.

Cooper, P. 2012. Socio-ecological accounting : DPSWR, a modified DPSIR framework, and its application to marine ecosystems. Ecological Economics. 94 (10) 106-115. DOI:10.1016/j.ecolecon.2013.07.010

De Jonge, VN \& M Elliott 2001. Eutrophication. In: J Steele, S Thorpe \& K Turekian (Eds.) Encyclopedia of Ocean Sciences. Volume 2, Academic Press, London.p852-870.

Ducrotoy, J-P \& M Elliott 2008. The science and management of the North Sea and the Baltic Sea: Natural history, present threats and future challenges, Marine Pollution Bulletin, 57: 8-21.

EC 2007 Council Regulation (EC) No 1098/2007 of 18 September 2007 establishing a multiannual plan for the cod stocks in the Baltic Sea and the fisheries exploiting those stocks, amending Regulation (EEC) No 2847/93 and repealing Regulation (EC) No 779/97

EEA, 1995. Europe's Environment: the Dobris Assessment. European Environmental Agency, Copenhagen.

Elliott, M. 2011. Marine science and management means tackling exogenic unmanaged pressures and endogenic managed pressures - a numbered guide. Marine Pollution Bulletin, 62: 651-655.

Elliott, M 2013. The 10-tenets for integrated, successful and sustainable marine management. Marine Pollution Bulletin 74(1): 1-5.

Elliott, M. 2014. Integrated marine science and management: wading through the morass. Marine Pollution Bulletin, 86(1/2): 1-4.

Elliott, M. D Burdon, KL Hemingway \& S Apitz 2007. Estuarine, Coastal and Marine Ecosystem Restoration: confusing management and science - a revision of concepts. Estuarine, Coastal \& Shelf Science 74: 349-366. 
Elliott, M., Borja, Á., McQuatters-Gollop, A., Mazik, K., Birchenough, S., Andersen, J.H., Painting, S., Peck, M., 2015. Force majeure: will climate change affect our ability to attain Good Environmental Status for marine biodiversity? Marine Pollution Bulletin, 95: 7-27.

Elliott, M., Borja, A., Atkins, J.P., Barnard, S., Boyes, S.J., Burdon, D., Cormier, R., de Jonge, V.N., Mazik, K., Smyth, K. and Turner, R.K. (submitted). A unifying framework for marine environmental management: DPSIR is dead, long live $\operatorname{DAPSI}(W) R(M) !$

Elmgren, R., and U. Larsson. 2001. Eutrophication in the Baltic Sea Area: Integrated Coastal Management Issues. In: von Bodungen, B. \& R.K. Turner, Eds. Science and Integrated Coastal Management. Berlin: Dahlem University Press, pp. 15-35

Elofsson, K. 2010. Baltic-wide and Swedish Nutrient Reduction Targets: An Evaluation of Cost-effective Strategies. Expertgruppen för Miljöstudier (Expert Group for Environmental Studies), Ministry of Finance, Stockholm

Fish, R., Burgess, J., Chilvers, J., Footitt, A., Turner, K. 2011. Participatory and Deliberative Techniques to support the monetary and non-monetary valuation of ecosystem services: an introductory guide. (Defra Project Code: NR0124). Department for Environment, Food and Rural Affairs: London. Available at: www.defra.gov.uk.

Fisher, B., Turner, R.K., Morling, P. 2009. Defining and classifying ecosystem services for decision-making. Ecological Economics 68: 643-653.

Gari, S. R., Newton, A., Icely, J. D. 2015. A review of the application and evolution of the DPSIR framework with an emphasis on coastal social-ecological systems. Ocean \& Coastal Management 103, 63-77.

Gilek, M., Lundberg, C., Renn, O., Wolowicz, M., Linke, S., Jönsson, A-M., Hassler, B., Boström, M., Karlsson, M., Hammer, M., Udovyk, O., Söderström, S., Linke, S., Bonsdorff, E., Grönholm, S., Haahti, B-M., Joas, M., Kern, K., Dreyer, M., Sellke, P., Zgrundo, A., Smolarz, K. and Lemke, P. 2011. Environmental Risk Governance of the Baltic Sea. Deliverable 12 within the RISKGOV project.

Gustafsson, B. G., Schenk, F., Blenckner, T., Eilola, K., Meier, H. E. M., Müller-Karulis, B., Neumann, T., Ruoho-Airola, T., Savchuk, O.P., and Zorita, E. 2012. Reconstructing the Development of Baltic Sea Eutrophication 18502006. AMBIO 41(6), 534-548. doi:10.1007/s13280-012-0318-x

Haasnoot, M., J. H. Kwakkel, W.E. Walker, and J. ter Maat. (2013) Dynamic adaptive policy pathways: A method for crafting robust decisions for a deeply uncertain world. Global Environmental Change 23:485-498. http://dx.doi.org/10.1016/j.gloenvcha.2012.12.006

Hassler, B. 2011. Accidental versus operational oil spills from shipping in the Baltic Sea Risk governance and management strategies. AMBIO 40(2): 170-178

HELCOM. 2007. Towards a Baltic Sea unaffected by eutrophication. HELCOM overview, 2007, Ministerial Meeting, Krakow, Poland, 15 November 2007. 35 pp

HELCOM. 2009. Biodiversity in the Baltic Sea - An integrated thematic assessment on biodiversity and nature conservation in the Baltic Sea. Baltic Sea Environmental Proceedings No. 116B. 
HELCOM. 2013. http://helcom.fi/Ministerial2013/ministerial-declaration/

Hyytiäinen K, Huhtala A, 2014. Combating eutrophication in coastal areas at risk for oil spills. Annals of Operation Research 219:101-121. DOI 10.1007/s10479-0110879-2

Hyytiäinen, K., Ahlvik, L., Ahtiainen, H., Artell, J., Huhtala, A., Dahlbo, K. 2015. Policy goals for improved water quality in the Baltic Sea: When do the benefits outweigh the costs? Environmental and Resource Economics 61: 217-241. DOI $10.1007 / \mathrm{s} 10640-014-9790-\mathrm{z}$

IPPC 2013 Climate Change 2013: The Physical Science Basis. Contribution of Working Group I to the Fifth Assessment Report of the Intergovernmental Panel on Climate Change. Stocker TF, Qin D, Plattner G-K, Tignor M, Allen SK, et al., editors Cambridge, United Kingdom and New York, NY, USA: Cambridge University Press. Available: http://www.climatechange2013.org/images/ uploads/WGI AR5 SPM brochure.pdf.

IPCC, 2014: Climate Change 2014: Impacts, Adaptation, and Vulnerability. Part B: Regional Aspects. Contribution of Working Group II to the Fifth Assessment Report of the Intergovernmental Panel on Climate Change [Barros, V.R., C.B. Field, D.J. Dokken, M.D. Mastrandrea, K.J. Mach, T.E. Bilir, M. Chatterjee, K.L. Ebi, Y.O. Estrada, R.C. Genova, B. Girma, E.S. Kissel, A.N. Levy, S. MacCracken, P.R. Mastrandrea, and L.L. White (eds.)]. Cambridge University Press, Cambridge, United Kingdom and New York, NY, USA, 688 pp.

Jentoft, S. 2007. Limits of governability: Institutional Implications for Fisheries and Coastal Governance. Marine Policy 31:360-370

Kahru, M. and Elmgren, R. 2014: Multidecadal time series of satellite-detected accumulations of cyanobacteria in the Baltic Sea, Biogeosciences, 11, 36193633, doi:10.5194/bg-11-3619-2014.

Karlsson, M., Gilek, M. and Udovyk, 0. 2011. Governance of Complex SocioEnvironmental Risks: The Case of Hazardous Chemicals in the Baltic Sea. AMBIO 40(2): 144-157

Kern, K. 2011. Governance for sustainable development in the Baltic Sea region. Journal of Baltic Studies 42(1): 67-81

Kwadijk, J. C. J., Haasnoot, M., Mulder, J. P. M., Hoogvliet, M. M. C., Jeuken, A. B. M., van der Krogt, R. A. A., van Oostrom, N. G. C., Schelfhout, H. A., van Velzen, E. H., van Waveren, H. and de Wit, M. J. M. 2010, Using adaptation tipping points to prepare for climate change and sea level rise: a case study in the Netherlands. WIREs Clim Change, 1: 729-740. doi: 10.1002/wcc.64

Laine A. 0. 2003. Distribution of soft-bottom macrofauna in the deep open Baltic Sea in relation to environmental variability. Estuarine Coastal and Shelf Science, 57:87-97. For changes in macrozoobenthos

Long R 2011. The marine strategy framework directive: a new European approach to the regulation of the marine environment, marine natural resources and marine ecological services. Journal of Energy and Natural Resources Law 29 (1): $1-44$ 
Leppäranta and Myrberg 2009. Physical oceanography of the Baltic Sea. Springer-Verlag, 378 pp. about the basic oceanography of the Baltic Sea.

Meier H.E.M, Andersson H, Arheimer B et al. 2012a. Comparing reconstructed past variations and future projections of the Baltic Sea ecosystem-first results from multi-model ensemble simulations. Environ. Res. Lett., 7, 034005.

Meier, H.E.M., Hordoir, R., Andersson, H.C., Dieterich, C., Eilola, K., Gustafsson, B.G., Höglund, A., Schimanke, S. 2012b. Modelling the combined impact of changing climate and changing nutrient loads on the Baltic Sea environment in an ensemble of transient simulations for 1961-2099. Clim Dyn DOI $10.1007 / \mathrm{s} 00382-012-1339-7$

MEA (Millennium Ecosystem Assessment) 2005. Ecosystems and human well-being: a framework for assessment. Island Press, Washington DC

Möllmann, C, Diekmann, R, Müller-Karulis, B, Kornilovs, G, Plikshs, M, and Axe, P. 2009. Reorganization of a large marine ecosystem due to atmospheric and anthropogenic pressure: a discontinuous regime shift in the Central Baltic Sea. Global Change Biology 15:1377-1393.

Niiranen S, Yletyinen J, Tomczak MT, Blenckner T, Hjerne O, Mackenzie BR, MüllerKarulis B, Neumann T and Meier HEM 2013. Combined effects of global climate change and regional ecosystem drivers on an exploited marine food web. Global Change Biology, 19:3327-3342.

Nyström, M., A. V. Norström, T. Blenckner, M. la Torre-Castro, J. S. Eklöf, C. Folke, H. Österblom, R. S. Steneck, M. Thyresson, \& M. Troell. 2012. Confronting Feedbacks of Degraded Marine Ecosystems. Ecosystems 15:695-710.

Öborn, I., Magnusson, U., Bengtsson, J., Vrede, K., Fahlbeck, E., Steen Jensen, E., Westin, C., Jansson, T., Hedenus, F., Lindholm-Schulz, H., Stenström, M., Jansson, B., Rydhmer, L. 2011. Five Scenarios for 2050 - Conditions for Agri-culture and land use. Uppsala, Swedish University of Agricultural Sciences.

OECD, 1993. OECD Core Set of Indicators for Environmental Performance Reviews. Organization for Economic Cooperation and Development, Paris.

O’Neill, B.C., Kriegler, E., Riahi, K., Ebi, K.L., Hallegatte, S., Carter, T.R., Mathur, R., van Vuuren, D.P. 2014. A new scenario framework for climate change research: the concept of shared socioeconomic pathways. Climatic Change 122: 387-400

Österblom, H., Hansson, S., Larsson, U., Hjerne, O., Wulff, F., Elmgren, R. and Folke, C. 2007. Human induced trophic cascades and ecological regime shifts in the Baltic Sea. Ecosystems 10: 877- 889.

Rockström, J., W. Steffen, K. Noone, Å. Persson, F. S. Chapin, III, E. Lambin, T. M. Lenton, M. Scheffer, C. Folke, H. Schellnhuber, B. Nykvist, C. A. De Wit, T. Hughes, S. van der Leeuw, H. Rodhe, S. Sörlin, P. K. Snyder, R. Costanza, U. Svedin, M. Falkenmark, L. Karlberg, R. W. Corell, V. J. Fabry, J. Hansen, B. Walker, D. Liverman, K. Richardson, P. Crutzen, and J. Foley. 2009. Planetary boundaries: exploring the safe operating space for humanity. Ecology and Society 14(2): 32.

Rosenau, J.N. 2003. Distant Proximities. Dynamics beyond Globalization. Princeton University Press. 
Rutgersson, A., J. Jaagus, F. Schenk, and M. Stendel. 2014. Observed changes and variability of atmospheric parameters in the Baltic Sea region during the last 200 years. Climate Research 61: 177-190.

Savchuk O. P., Wulff, F., Hille S., Humborg C., Pollehne F. 2008. The Baltic Sea a century ago - a reconstruction from model simulations, verified by observations. Journal of Marine Systems 74 (485-494)

Spash, C. L. 2007. Deliberative monetary valuation (DVM): issues in combining economic and political processes to value environmental change. Ecological Economics 63: 690-699.

Spash CC 2008. Deliberative monetary valuation and the evidence for a new value theory. Land Econ 84:469-488

SwAM 2013. The Baltic Sea- Our common treasure: Economics of saving the sea. BalticStern Report

Söderqvist, T., Brinkhoff, P., Norberg, T., Rosén, L., Back, P-E., Norrman, J., 2015. Costbenefit analysis as a part of sustainability assessment of remediation alternatives for contaminated land. Journal of Environmental Management 157, 267-278.

Telesh, I.V., Schubert, H., and Skarlato, S.O. 2011. Revisiting Remane's concept: evidence for high plankton diversity and a protistan species maximum in the horohalinicum of the Baltic Sea, Marine Ecology Progress Series 421: 1-11.

Tett P., Gowen R., Painting S., Elliott M., Foster R., Mills D., Bresnan E., Capuzzo E., Fernandes T., Foden J., Geider R., Gilpin L., Huxham M., McQuatters-Gollop A., Malcolm S., Saux-Picart S., Platt T., Racault M.-F., Sathyendranath S., Molen J.v.d. and Wilkinson M. 2013. Framework for understanding marine ecosystem health. Marine Ecology Progress Series 494: 1-27 + suppl. material.

Turner R.K. , Lorenzoni I et al 1998. Coastal management for sustainable development: analysing environmental and socio-economic changes on the UK coast, Geographical Journal 164:269-281.

Turner R.K. 2000. Integrating natural and socio-economic science in coastal management, Journal of Marine Systems 25:447-460.

Turner R.K., Subak S and Adger N 1996. Pressures,trends and impacts in coastal zones; interactions between socio-economic and natural systems Environmental Management 20:159-173.

Turner R.K. 2007. Limits to CBA in UK and European environmental policy: retrospects and future prospects. Environmental and resource Economics 37:253-269.

Turner, R.K. \& Schaafsma, M. (Eds.) 2015. Coastal zones ecosystem services: from science to values and decision making. Springer Ecological Economic Series, Springer Internat. Publ. Switzerland, ISBN 978-3-319-17213-2

Turner R.K. 2016. The 'balance sheet' approach within adaptive management for ecosystem services. In M. Potschin, R. Haines-Young, R.Fish and R Kerry Turner eds (2016) Routledge Handbook of Ecosystem Services, Earthscan, Routledge, Abingdon, Oxon, UK, ch 23 pp289-299. 
UKNEA FO 2014 UK National Ecosystem Assessment The UK National Ecosystem Assessment: Synthesis of the Key Findings. UNEP-WCMC, LWEC, UK.

UNEP 2012. 5th Global Environment Outlook (GEO-5)

Valman, M. 2013. Institutional stability and change in the Baltic Sea: 30 years of issues, crisis and solutions. Marine Policy 38: 54-64

Wise, R.M., I. Fazey, M. Stafford Smith, S.E. Park, H.C. Eakin, E.R.M. Archer Van Garderen and B. Campbell. 2014. Reconceptualising adaptation to climate change as part of pathways of change and response. Global Environmental Change 28:325336.

Voipio A, 1981. The Baltic Sea. Elsevier Oceanography Series 30, References to be added to reference list end of article:EC (2007) Council Regulation (EC) No. $1098 / 2007$.

Wolanski, E, Elliott M 2015. Estuarine Ecohydrology: an introduction. Elsevier, Amsterdam, ISBN 978-0-444-63398-9, pp322.

WWF. 2012. Counter currents: scenarios for the Baltic Sea towards 2030. 